\title{
Imaging of bilateral Ask-Upmark kidney
}

\author{
Hiroshi Komatsu' ${ }^{1} \cdot$ Teruki Aoi $^{1} \cdot$ Ichiro Yamazoe $^{2}$
}

Received: 31 January 2018 / Accepted: 6 March 2018 / Published online: 16 March 2018

(c) The Author(s) 2018

\begin{abstract} kidneys. Our case indicates that the pathogenesis of this condition is most likely related to developmental anomalies.

Keywords Renal segmental hypoplasia · Ask-Upmark kidney · Hypertension · Dimercaptosuccinic acid scan · Computed tomography
\end{abstract}

Unique radiologic features of Ask-Upmark kidney were reported. A contrast-enhanced computed tomography showed lobulated cortical thinning. Renal dimercaptosuccinic acid scan revealed isolated circular accumulations mimicking accessory

\section{Abbreviations}

AUK Ask-Upmark kidney

An 8-year-old boy was referred to our hospital with proteinuria. He was found to be hypertensive $(145 / 110 \mathrm{mmHg})$ and had no history of urinary tract infection. The laboratory investigation revealed an elevated serum creatinine level of $0.66 \mathrm{mg} / \mathrm{dL}$ (97.5th percentile for the patient's age group is $0.53 \mathrm{mg} / \mathrm{dL}$ ). The serum aldosterone level and plasma renin activity were marginally increased $(186.0 \mathrm{pg} / \mathrm{mL}$ and $7.1 \mathrm{ng} /$ $\mathrm{mL} / \mathrm{h}$, respectively, in a recumbent position after rest. Normal values; $29.2-159.0 \mathrm{pg} / \mathrm{mL}$ and $0.2-2.3 \mathrm{ng} / \mathrm{mL} / \mathrm{h}$, respectively). No bacteriuria was observed. Renal ultrasonography showed deeply cleaved parenchyma in the lower part of the bilateral kidneys. Renal dimercaptosuccinic acid scanning revealed severe defects, with circular accumulations in the lower part of each kidney. These abnormalities did not resemble the wedge-shaped defects typically seen in cases of renal scarring (Fig. 1). A voiding cystourethrogram revealed no reflux and a large amount (over $130 \mathrm{~mL}$ ) of residual urine, which was suggestive of bladder dysfunction. In the

Hiroshi Komatsu

hkoma6019@hosp.go.jp

1 Department of Pediatrics, National Hospital Organization Maizuru Medical Center, 2410 Yukinaga, Maizuru, Kyoto 625-8502, Japan

2 Yamazoe Pediatric Clinic, 2030 Iwataki, Yosano-cho, Yosa-gun, Kyoto 629-2262, Japan

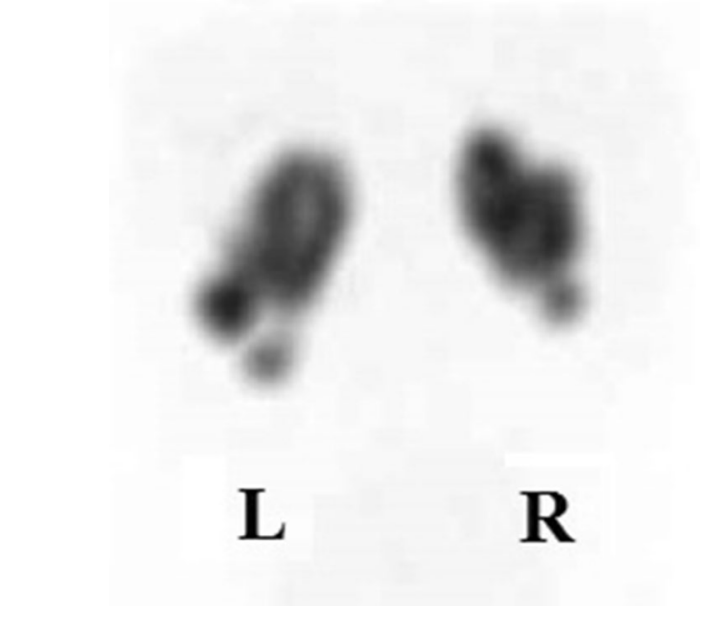

Fig. 1 A renal dimercaptosuccinic acid scan revealed isolated circular accumulations in the lower polar regions of the both kidneys, mimicking accessory kidneys

arterial phase of a contrast-enhanced computed tomography, lobulated cortical thinning with dilated calyces in the lower parts of both kidneys was identified. This was observed as smooth indentations of the renal outline between the pyramids, which is in contrast to that observed in renal scarring, wherein the indentation is not smooth and often overlies the renal pyramids. Furthermore, the lower parts of the bilateral ureters were dilated (Fig. 2). The patient's blood pressure was successfully controlled with an angiotensin converting enzyme inhibitor, and was stabilized at $120 / 70 \mathrm{mmHg}$, with elevated serum aldosterone levels and plasma renin activity (274.0 pg/mL and $20.7 \mathrm{ng} / \mathrm{mL} / \mathrm{h}$, respectively). Renal segmental hypoplasia, known as Ask-Upmark kidney (AUK), is an extremely rare renal abnormality, grossly characterized by one or more sharply separated hypoplastic segments that overlie the dilated calyces and are retracted with capsular grooving $[1,2]$. The radiological findings in this patient were 


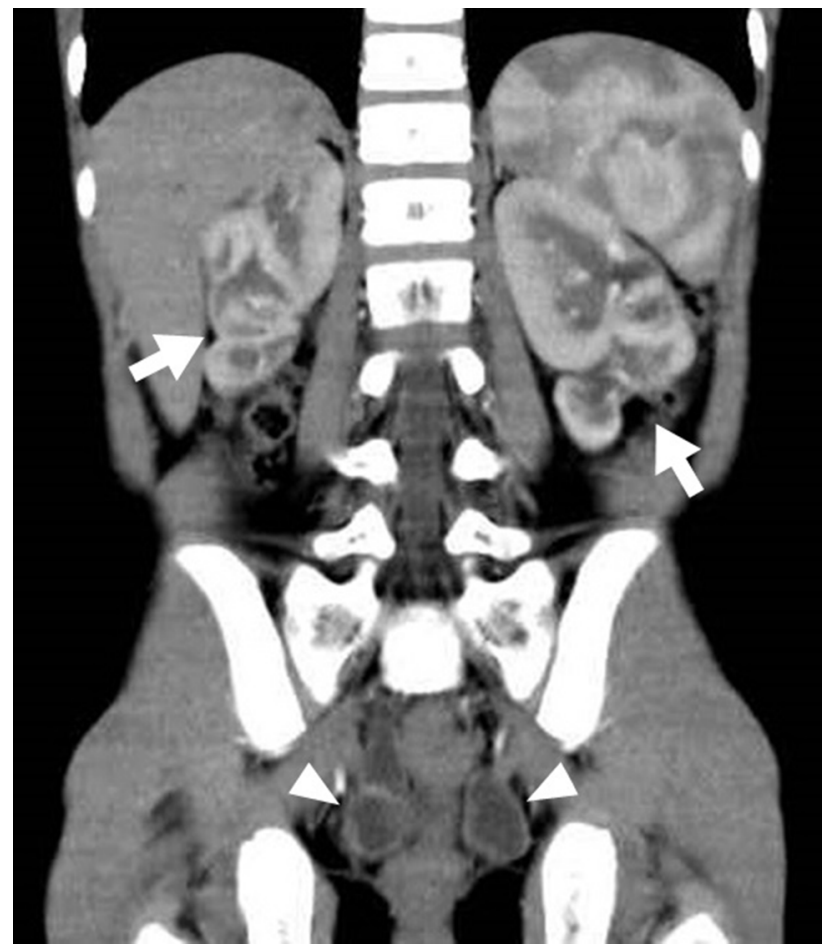

Fig. 2 The arterial phase of a coronal computed tomography image after intravenous contrast enhancement. This image demonstrates segmental cortical thinning, especially in the bilateral lower moieties (arrows). Note the smooth indentation of the renal outline between the pyramids, and the bilateral dilation in the lower part of the ureters (arrow heads)

consistent with AUK. Although a strict diagnosis must be made on the basis of the pathology, appropriate radiologic examinations make a non-invasive diagnosis of AUK possible. The pathogenesis of this condition is controversial [1-3]. However, the case we described here indicates that the pathogenesis of AUK is most likely related to developmental anomalies of the kidneys and the urinary tract, rather than renal scarring. AUK should be considered as a potential cause of proteinuria, hypertension, or renal insufficiency.

\section{Compliance with ethical standards}

Conflict of interest The authors have no conflict of interest to declare.

Human and animal rights statement This article does not contain any studies with human participants or animals.

Informed consent Informed consent was obtained from all individual participants included in the study.

Open Access This article is distributed under the terms of the Creative Commons Attribution 4.0 International License (http://creativeco mmons.org/licenses/by/4.0/), which permits unrestricted use, distribution, and reproduction in any medium, provided you give appropriate credit to the original author(s) and the source, provide a link to the Creative Commons license, and indicate if changes were made.

\section{References}

1. Jeannette JC, Olsen JL, Schwartz MM. Distinct Types of Reflux Ask-Upmark Kidney. In: lippincott-Raven, editor. Heptinstall's Pathology of the Kidney. 6th ed. Philadelphia: Lippincott-Raven; 2007. pp. 1037-8.

2. Gigante A. Ask-Upmark kidney and tubulointerstitial nephritis in a woman with severe renal failure. Ren Fail. 2011;3:726-9.

3. Prasad S. Ask-Upmark Kidney. A Report of 2 Cases. Int J Health Sci Res. 2013;3:61-4. 